\title{
Controllable Aligned Nanofiber Hybrid Yarns with Enhanced Bioproperties for Tissue Engineering
}

DOI:

10.1002/mame.201900089

\section{Document Version}

Accepted author manuscript

Link to publication record in Manchester Research Explorer

\section{Citation for published version (APA):}

Liu, C., Li, B., Mao, X., Zhang, Q., Sun, R., Gong, R. H., \& Zhou, F. (2019). Controllable Aligned Nanofiber Hybrid Yarns with Enhanced Bioproperties for Tissue Engineering. Macromolecular Materials and Engineering, [1900089]. https://doi.org/10.1002/mame.201900089

\section{Published in:}

Macromolecular Materials and Engineering

\section{Citing this paper}

Please note that where the full-text provided on Manchester Research Explorer is the Author Accepted Manuscript or Proof version this may differ from the final Published version. If citing, it is advised that you check and use the publisher's definitive version.

\section{General rights}

Copyright and moral rights for the publications made accessible in the Research Explorer are retained by the authors and/or other copyright owners and it is a condition of accessing publications that users recognise and abide by the legal requirements associated with these rights.

\section{Takedown policy}

If you believe that this document breaches copyright please refer to the University of Manchester's Takedown Procedures [http://man.ac.uk/04Y6Bo] or contact uml.scholarlycommunications@manchester.ac.uk providing relevant details, so we can investigate your claim.

\section{OPEN ACCESS}


DOI: $10.1002 /(($ please add manuscript number))

\section{Article type: Full Paper}

Controllable aligned nanofiber hybrid yarns with enhanced bioproperties for tissue engineering

Chengkun Liu,* Boyu Li, Xue Mao, Qing Zhang, Runjun Sun, R Hugh Gong, Fenglei Zhou

Prof. C. Liu, Dr. X. Mao, Mr. Q. Zhang, Prof. R. Sun

School of Textile Science and Engineering

Xi'an Polytechnic University

Xi'an Shaanxi 710048, China

Email: liuchengkun@xpu.edu.cn

Dr. B. Li

School of Materials Science \& Engineering

Materials Institute of Atomic and Molecular Science

Shaanxi University of Science and Technology

Xi'an Shaanxi 710021, China

Prof. C. Liu, Prof. R. H. Gong, Prof. F. Zhou

The School of Materials

The University of Manchester

Manchester M13 9PL, UK

Prof. F. Zhou

Center for Imaging Sciences 
The University of Manchester

Manchester M13 9PL, UK

Keywords: electrospinning, aligned nanofibers, microfibers, core-shell yarn, tissue engineering

\begin{abstract}
Electrospun nanofibers have large surface area, high porosity and controllable orientation while conventional microfibers have appropriate mechanical properties such as stiffness, strength, and elasticity. Therefore, the combination of nanofibers and microfibers can provide building elements to engineer biomimetic scaffolds for tissue engineering. In this study, a core-shell structured fibrous structure with controllable surface topography was created by electrospinning polycaprolactone (PCL) nanofibers onto polyglycolic acid (PGA) microfibers. The surface morphology, surface wettability and mechanical properties of resultant core-shell structure were characterized. FE-SEM images reveal that the orientation of PCL nanofibers on the yarn surface can be tuned by the fiber collector and rotating disks. Benefiting from the introduction of the shell of aligned PCL nanofibers on the core of PGA yarn, the uniaxially aligned PCL nanofiber covered yarns (A-PCLs) exhibited higher hydrophilicity, porosity, and mechanical properties than the core PGA yarns. Moreover, A-PCLs promoted the adhesion and proliferation of BALB/3T3 (mouse embryonic fibroblast cell line), and guided cell growth along the biotopographic cues of the PCL nanofibers with controllable alignment. The developed core-shell yarn that can have both the desired surface topography of PCL nanofibers and mechanical properties of PGA microfibers has demonstrated great potential in constructing various tissue scaffolds.
\end{abstract}




\section{Introduction}

Tissue engineering, also known as regenerative medicine, is based on biological and engineering disciplines, and it mainly refers to the preparation of human tissue substitutes to promote the repair of human injury tissue or organ. ${ }^{[1]}$ Extracellular matrix (ECM) primarily containing some polysaccharides and proteins is a micro-nanoscale network of macromolecules distributed on the cell surface or among cells. ${ }^{[2]} \mathrm{ECM}$ can provide a suitable microenvironment for cell behavior, and affect the cell shape, metabolism, function, migration, proliferation and differentiation through the biophysical and biochemical signal. ${ }^{[3,4]}$ One of the main research contents of tissue engineering is to generate the biocompatible scaffold that will imitate ECM and three-dimensional (3D) structure of diverse tissues. Recently, some properties of the 3D bioengineered scaffold including strength, porosity and configuration have been examined to improve diverse ECM platforms. ${ }^{[5,6]}$ In particular, there have been numerous reports on cell growth and related behavior of 3D scaffolds which possessed aligned biotopographical cues due to the regular organization of most of the structures of native tissues. ${ }^{[7-9]}$ For example, skeletal muscle tissue is composed of aligned myofibers, and blood vessel is made up of aligned vascular endothelial cells along the axial direction. Various methods such as freeze-drying, ${ }^{[10]}$ molecular self-assembly, ${ }^{[11]}$ photo-lithography, ${ }^{[12]}$ micro-grooving, ${ }^{[13]} 3 \mathrm{D}$ printing ${ }^{[14]}$ have been employed for the preparation of 3D well-organized tissue scaffolds. However, in clinical and commercial considerations, these methods involve complex process, expensive cost, or low resolution, and are difficult to adapt to the complexity of the size, configuration, and strength of the target tissue/organ. 
the ancients used cotton or flax to suture the wound. ${ }^{[15]}$ At present, different textile structures including woven, knitted and nonwoven fabrics have been used as supports for tissue/organ repairing/regeneration, such as $3 \mathrm{D}$ woven cartilage scaffold, nonwoven scaffolene ${ }^{\circledR}$ and $3 \mathrm{D}$ knitted cardiac scaffold. ${ }^{[16,17]}$ They have 3D structures and can be served as guiding and ECM mimicking structures for soft tissue, ligament or cartilage. However, cells cultured on conventional scaffolds made of macroscale fiber or yarn materials lack sufficient contact guidance so that cells cannot effectively deposit ECM mimics to generate a micro-nanoscale environment that can promote growth, differentiation, and migration. ${ }^{[18]}$ Electrospinning is a well-established technology for the production of nanofibers, which was first reported by Formhals. ${ }^{[19]}$ Besides low cost and simple operation, some of the known features of electrospun fibers include a large specific surface area, nano-sized diameter, and high porosity. ${ }^{[20,21]}$ Aligned electrospun fibers or yarn prepared by the modified electrospinning process can provide improved mechanical properties and effective biotopographic cues highly desired by anisotropic tissue scaffolds such as tendon, ligament and cardiac tissues. ${ }^{[22,23]}$ It was also found that aligned electrospun nanofibers could promote adhesion and growth of some cells (nerve, smooth muscle cells, and myofiber, etc.). ${ }^{[24-27]}$ Electrospun aligned nanofibers with sufficient mechanical strength can be used as scaffolds alone or combined with textile technologies such as weaving, knitting or braiding to engineer 3D nanofiber scaffolds. The resultant scaffolds can effectively simulate the microstructure of ECM to a great extent, including simulation of the 3D structure of heart, ${ }^{[28,29]}$ muscle,${ }^{[30-32]}$ vascularization, ${ }^{[33]}$ nerves, ${ }^{[34,35]}$ and cartilage. ${ }^{[36-37]}$ However, pure electrospun fibers remain 
challenging to process into 3D structures due to low mechanical properties, and therefore limit their practical uses. For example, the tensile strength of nanofiber yarn scaffolds for skeletal muscle tissues reported by Wang et al. ${ }^{[30]}$ was less than $\sim 5 \mathrm{cN}(1 \mathrm{MPa})$, which failed to meet the requirement in the repair of tendons and ligaments that usually have tensile strength from 15 to $100 \mathrm{MPa} \cdot{ }^{[38]}$ To overcome this limitation, the concept of core-shell yarns has been conceived and tested on a specially designed electrospinning setup. ${ }^{[39]}$ This method combines conventional bio-braided fibers acting as the core materials to provide the required strength for post processing, with aligned electrospun nanofibers serving as the shell to provide biotopographic cues.

In this study, core-shell yarns with tunable nanofiber orientations on the surface were developed and their effects on hydrophilicities, mechanical properties, and in vitro biological performance as tissue scaffolds were assessed. Aligned polycaprolactone (PCL) nanofibers beneficial to the promotion of cell adhesion and growth were electrospun onto polyglycolic acid (PGA) yarns, which were biocompatible and could provide an excellent mechanical strength and a stable size. The morphological structure of the scaffolds composed of aligned PCL nanofiber covered yarns (A-PCLs) was analyzed by SEM, and the BALB/3T3 (mouse embryonic fibroblast cell line) cells were cultured on these scaffolds. The effect of nanofiber arrangement on performance of the scaffolds in terms of cell morphology, adhesion, and growth was also evaluated. Results showed that the scaffolds with controllable aligned nanofibers possessed controllable guidance for cell growth, and the mechanical properties of the scaffolds reached practical level (372 MPa) for weaving or other post-treatments. Aligned PCL nanofibers on the surface could also improve the hydrophilicity (surface contact angle 
reduced from $134^{\circ}$ to $94^{\circ}$ ) and porosity (increased from 19\% to 90\%) of the scaffolds. This type of nanofiber covered yarn can potentially be used in the biomedical textiles such as 3D scaffolds for diverse tissue engineering applications.

\section{Experimental Section}

Materials: The PGA yarn sized $2(\sim 0.5 \mathrm{~mm}$ diameter $)$ was purchased from Shandong WeiGao Group Medical Polymer Co., Ltd., China. PCL (Mn=80000) (Sigma-Aldrich, MO, USA) solution with the concentration of $10 \mathrm{wt} \%$ was prepared by dissolving it in $60 / 40(\mathrm{v} / \mathrm{v})$ mixture of dichloromethane (DCM) and N,N-dimethylformamide (DMF) (Tianjin Kermel Chemical Reagents Co., Ltd., China). PGA yarn and PCL were chosen as raw materials, because PGA yarn exhibits good biocompatibility and is often used as the suture, and PCL shows good biocompatibility and biodegradability. DCM and DMF were used without further purification. BALB/3T3 cells were obtained from the Cell Bank of the Chinese Academy of Sciences (Shanghai, China). Medium and other reagents for cell culture were purchased from Hyclone (USA).

Fabrication of nanofiber covered yarn scaffolds: The electrospinning setup comprises of a syringe pump (Zhejiang Smith Medical Instrument Co., Ltd., China), a high voltage power supply (Dalian ZhiDian Electronic Technology Co., Ltd.,China), a grounded collector (consisted of two parallel aluminum flakes), and two rotating disks with two rotating rollers. In the electrospinning process, PCL solution in a $20 \mathrm{~mL}$ syringe was pushed by a syringe pump at an infusion rate of $0.8 \mathrm{~mL} \mathrm{~h}^{-1}$ to a spinneret with the inner diameter of $1.65 \mathrm{~mm}$. Two parallel aluminum flakes (length of $20 \mathrm{~cm}$, span distance of $3 \mathrm{~cm}$ ) were used as the grounded collectors below the spinneret. A voltage of $15 \mathrm{kV}$ was applied between the spinneret and the 
grounded collector. The distance between the spinneret tip and the upper edges of collector was $15 \mathrm{~cm}$. When aligned PCL nanofibers were suspended over the edges of the two parallel aluminum flakes, PGA yarn was conveyed at a controlled speed into the spinning zone by an unwinding roller. Meanwhile, two disks were rotated at the same speed and direction to allow the aligned PCL nanofibers to uniformly cover the PGA yarn and form a core-shell structure. This electrospinning process was carried out at $20 \pm 2{ }^{\circ} \mathrm{C}$ and $65 \pm 5 \mathrm{RH} \%$. All prepared scaffolds were kept in a ventilated environment for $24 \mathrm{~h}$ to allow any residual organic solvent to evaporate completely.

Characterization of scaffolds: The morphology of scaffolds was characterized by a field emission scanning electron microsope (FE-SEM) (Quanta-450-FEG, FEI, England). FE-SEM images were analyzed using Smileview (JEOL) software to determine fiber diameter and pore diameter through the selection of five random fields of each image. Optical images of the prepared yarns were recorded by a digital camera (HDR-SR11E, SONY, Japan). Modified Fast Fourier Transform (MFFT) technique was employed to characterize the alignment of nanofibers from the FE-SEM images. ${ }^{[40,41]}$ The porosity of scaffolds was measured according to the liquid displacement method. ${ }^{[42]}$ Before test, scaffolds were placed in a desiccator (Shanghai SuoPu Instrument Co., Ltd., China) for drying $2 \mathrm{~h}$ and were then put into measuring cylinders that were filled with a certain volume of ethanol. The porosity $(P)$ of scaffolds was calculated as follows:

$$
P(\%)=\frac{V_{1}-V_{3}}{V_{2}-V_{3}} \times 100 \%
$$


Where $V_{1}$ is the volume of ethanol in a measuring cylinder, $V_{2}$ refers to the volume of ethanol and scaffold; $V_{3}$ is the volume of remaining ethanol after the scaffold was taken out.

Mechanical properties of scaffolds were evaluated by an electronic strength tester (5565, Instron, USA). All scaffolds for testing were cut into $15 \mathrm{~cm}$ and pulled at a speed of $10 \mathrm{~mm}$ $\min ^{-1}$. To study the hydrophilicity of scaffolds, water contact angle was measured with $2 \mu \mathrm{L}$ water using a contact angle analyzer (OCA15EC, Dataphysics, Germany) at ambient temperature. The morphology of water drops at randomly distributed positions of the scaffolds was recorded and then analyzed. Wicking height $(W)$ was utilized to evaluate water absorption capacity of scaffolds by a wicking property tester (YG(B)871, China). The average value of $W$ was calculated as follows:

$$
W=\frac{\sum_{i=1}^{n} w_{i}}{n}
$$

Where $w$ is the height of the water along the fiber.

Biological assessment in vitro: BALB/3T3 cells were cultured in DMEM culture medium with $10 \%$ FBS and $1 \%$ antibiotics. All prepared scaffolds were placed in the bottom of 24-well tissue culture plate (TCP), washed 3 times with PBS, sterilized for $12 \mathrm{~h}$ under UV radiation, and subsequently incubated with DMEM for $24 \mathrm{~h}$ before cell seeding. Cells were detached by trypsin/EDTA when cells were grown to $90 \%$ confluency. A hemocytometer was used to count the viable cells and then cells were seeded onto scaffolds at a density of $1 \times 10^{4}$ cells/well. Afterwards, cells were cultured in the standard culture condition $\left(37{ }^{\circ} \mathrm{C}, 5 \% \mathrm{CO}_{2}\right.$, and $95 \%$ humidity). The medium was refreshed every $48 \mathrm{~h}$. To study the cell proliferation on different scaffolds, viable cells were determined by using methylthiazol tetrazolium (MTT) 
assay. After 1, 3, and 5 days of cell seeding in a 24-well plate, cells were washed with PBS and incubated in $400 \mu \mathrm{L}$ MTT solution. After incubation at the standard culture condition for $3 \mathrm{~h}$, the MTT solution was removed from each well and $400 \mu \mathrm{L}$ DMSO was appended. The plate was gentlely shaked for $20 \mathrm{~min}$ in order to dissolve the formazan precipitate. A spectrophotometric plate reader was used to measure the absorbance of the content of each well at $492 \mathrm{~nm}$. Cells grown on the $24-w e l l$ TCP was used as the control. The morphology of cells on scaffolds was examined by FE-SEM. After 3 days culture, cell-scaffolds were washed with PBS and fixed with 3\% glutaraldehyde for $2 \mathrm{~h}$, followed by dehydrating through gradient ethanol solution $(30,50,70,90,100 \% \mathrm{v} / \mathrm{v})$ and drying $12 \mathrm{~h}$ at room temperature. Completely dried cell-scaffolds were coated with gold for the analysis of cell morphology. The elongation of BALB/3T3 cells on prepared scaffolds was measured by aspect ratio, which was evaluated by the longest and shortest length of cell on FE-SEM images. Confocal laser scanning microscope (CLSM) (FV1200, Olympus, Japan) was used to visualize cell cytoskeletal structure and distribution on the scaffolds. The process can be briefly described as follows: cell-scaffolds were washed three times with PBS, fixed with 4\% paraformaldehyde for $60 \mathrm{~min}$, permeabilized with $1 \mathrm{~mL}$ 0.1\% Triton X-100 (AMRESCO USA) for $10 \mathrm{~min}$ after culture of 3 days. The cells on scaffolds were stained for $30 \mathrm{~min}$ with FITC-Phalloidin and then stained by DAPI for 5 min after being washed another three times with PBS. The nuclei and cytoskeletons of cells were finally visualized by CLSM. The alignment of cells was determined from CLSM images by MFFT technique. 


\section{Results and discussion}

\subsection{Morphology and characterization of the prepared scaffolds}

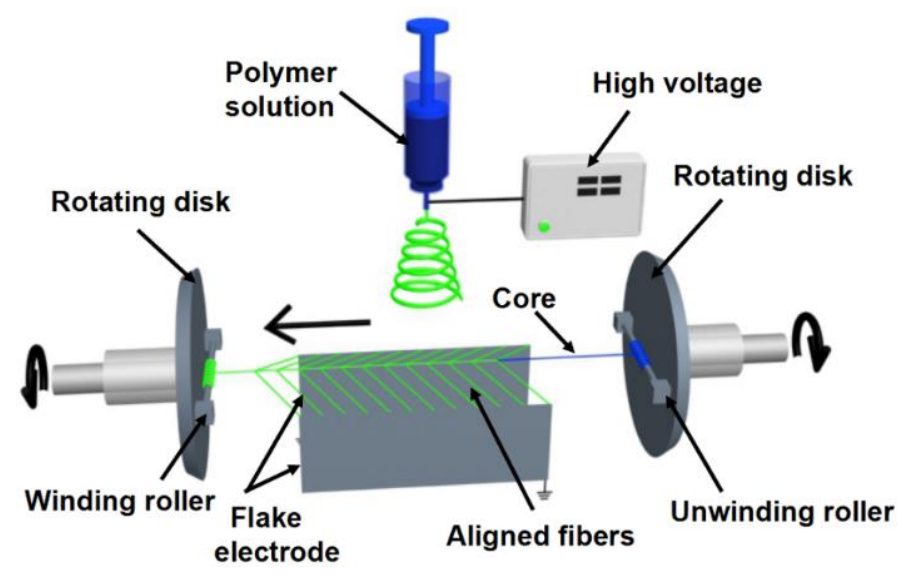

Figure 1. Schematic of the device used to prepare A-PCLs.

First, A-PCLs were prepared by homemade electrospun apparatus (Figure 1), which have been reported in our previous work. ${ }^{[39,43]}$ In brief, the morphology of the A-PCLs was affected by the speed of the unwinding rollers and rotating disks. The rotation of the disks controls the covering cycle of PCL nanofibers onto the PGA yarn. Figure 2a, b, and c show the prepared A-PCLs at 300, 500, and 700 rpm disk speeds. The speed of the winding and unwinding rollers was fixed at $30 \mathrm{rpm}$. The resultant A-PCLs named as 300-PCLs, 500-PCLs, and 700-PCLs have different nanofiber alignment angles (the angle between direction of nanofibers and axial direction of the core yarn). It is found that the angle of the PCL nanofibers along the axial direction increases from $3^{\circ}$ through $35^{\circ}$, to $85^{\circ}$ with the increase of the rotation speed, indicating that the nanofibers are close to the axial direction at a lower rotation speed and close to vertical direction at a higher rotation speed. It is for this reason 
that this method allows us to design different scaffold materials which have different topographic cues as needed. We can also change the raw polymer materials or add drugs into the nanofibers according to requirements through this process. Random PCL nanofiber membranes (R-PCLs) were manually wrapped on the core yarn at the same electrospinning time and used as the control scaffold (Figure S1a). The surface morphology of R-PCLs is shown in Figure $\mathbf{S} 1 \mathrm{~b}$.

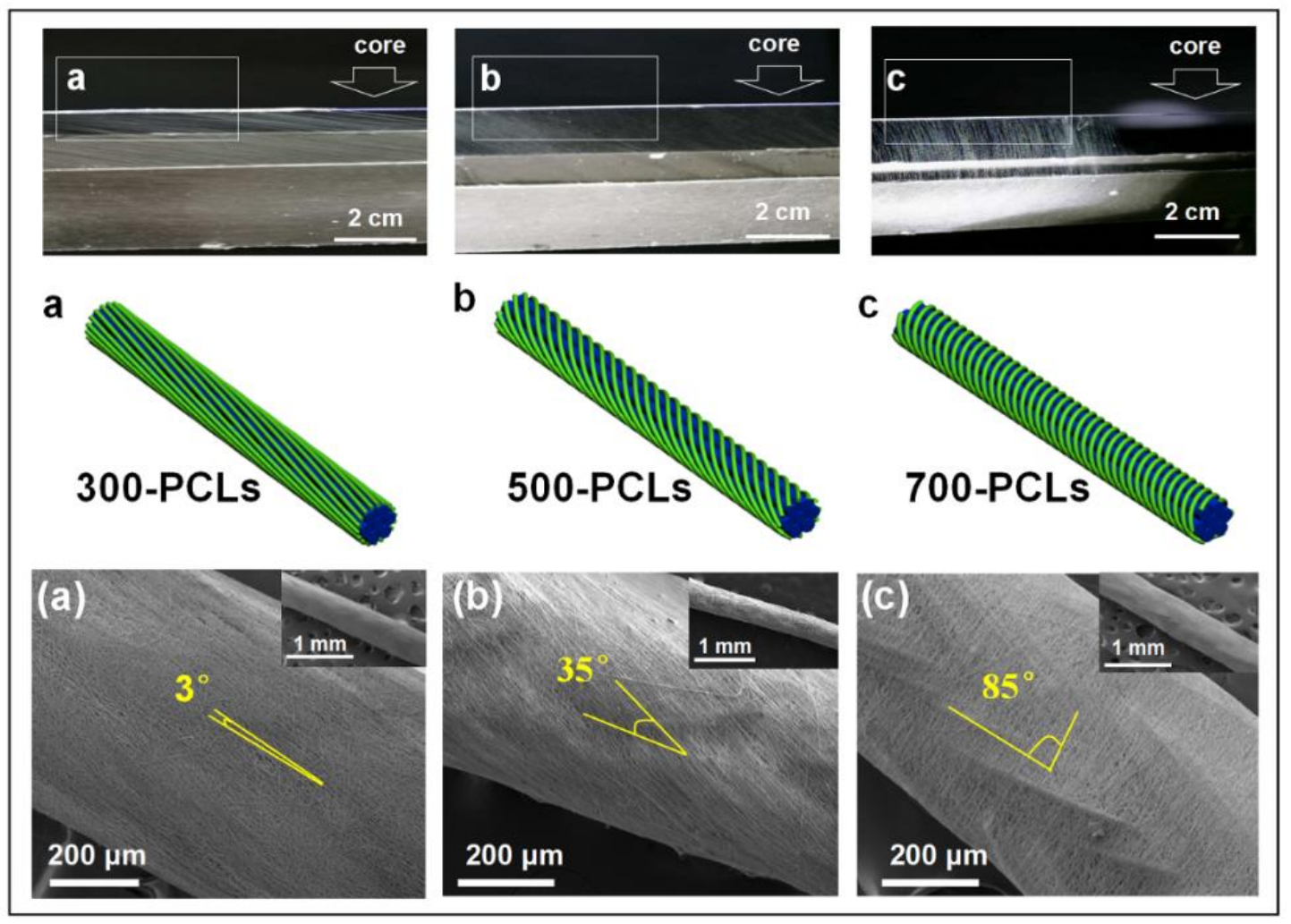

Figure 2 Schematic illustration of the A-PCLs fabrication procedure: (a)-(c) Fabrication process and surface morphology for the 300-PCLs, 500-PCLs, 700-PCLs.

FE-SEM images in Figure 2a-c show that the surface of 300-PCLs, 500-PCLs, and 700-PCLs was smooth and nanofibers were aligned at an increasing angle from $3^{\circ}, 35^{\circ}$, to $85^{\circ}$ with reference to the axial direction. Surface morphology images (Figure 3a-c) and corresponding fiber alignment curves (Figure 3a'-c') show that nanofibers on the scaffolds were neatly aligned with peaks of $3^{\circ}, 35^{\circ}$, and $85^{\circ}$, respectively. This further proves the 

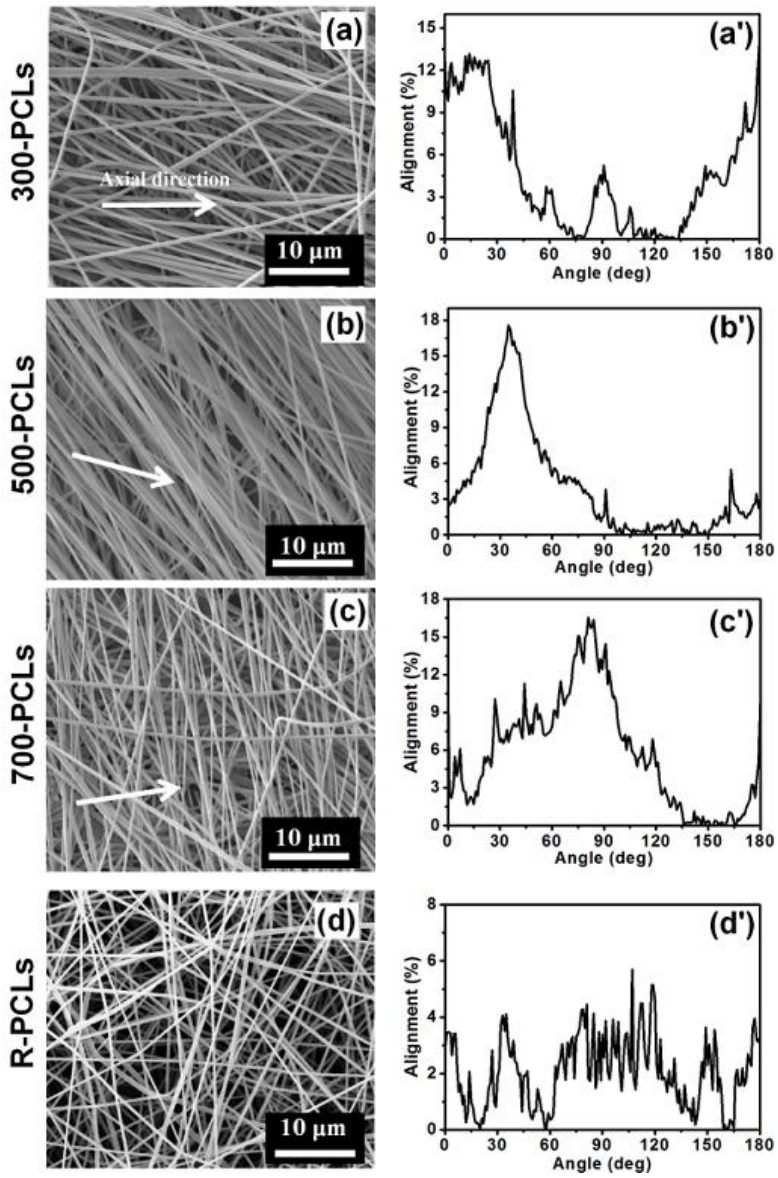

Figure 3 FE-SEM images of different scaffolds at a high magnification (a)-(d) and corresponding curves of fiber arrangement on the surface of different scaffolds (a')-(d').

Table 1 Fiber diameter, pore diameter and porosity of different scaffolds. ${ }^{*}, p<0.05$.

\begin{tabular}{cccc}
\hline Substrate & Fiber diameter $(\mathrm{nm})$ & Pore diameter $(\mathrm{nm})$ & Porosity $(\%)$ \\
\hline Core & - & - & $19.01 \pm 3.89^{*}$ \\
R-PCLs & $443.5 \pm 59$ & $1482 \pm 334$ & $76.38 \pm 5.73$ \\
$300-$ PCLs & $387.7 \pm 33$ & $2281 \pm 836$ & $89.97 \pm 6.74$ \\
$500-P C L s$ & $414.8 \pm 31$ & $1914 \pm 773$ & $85.66 \pm 7.07$ \\
$700-P C L s$ & $348.6 \pm 43$ & $2194 \pm 640$ & $84.28 \pm 7.16$ \\
\hline
\end{tabular}

\subsection{Effect of nanofiber arrangement on hydrophilicity of different scaffolds}

Hydrophilicity of the scaffold is the key issue for cell adhesion and proliferation, because hydrophilicity can affect the adhesion of serum proteins. ${ }^{[46]}$ Figure 4 presents the 
hydrophilicity of different scaffolds including surface contact angle analysis and wicking effect measurement. The water contact angle of 300-PCLs, 500-PCLs, and 700-PCLs is $94 \pm 5^{\circ}, 97 \pm 7^{\circ}$, and $109 \pm 6^{\circ}$, respectively, which are significantly lower than that of R-PCLs $\left(134 \pm 8^{\circ} ; P<0.05\right)$ shown in Figure 4a. Wicking effect is usually used in the textile field to characterize the hydrophilicity of fibers or yarns. Figure $4 \mathrm{~b}$ gives the wicking height of different scaffolds. It is evident that the wicking property of the core yarn improved significantly when the yarn surface were covered with aligned nanofibers. Wicking height of 300-PCLs $(10.4 \pm 0.7 \mathrm{~cm}), 500$-PCLs $(9.3 \pm 0.8 \mathrm{~cm})$, and 700 -PCLs $(9.0 \pm 0.8 \mathrm{~cm})$ exhibit a slight decrease but they are all higher than that of R-PCLs $(8.3 \pm 0.6 \mathrm{~cm})$. The reason behind this result can be explained as wicking effect according to our previous study. ${ }^{[39]}$ More capillaries formed between aligned nanofibers are beneficial to water diffusion. The increase of alignment angle results in a more inclined route and greater resistance to water diffusion. However, R-PCLs have more inefficient capillaries because of random fiber arrangement.
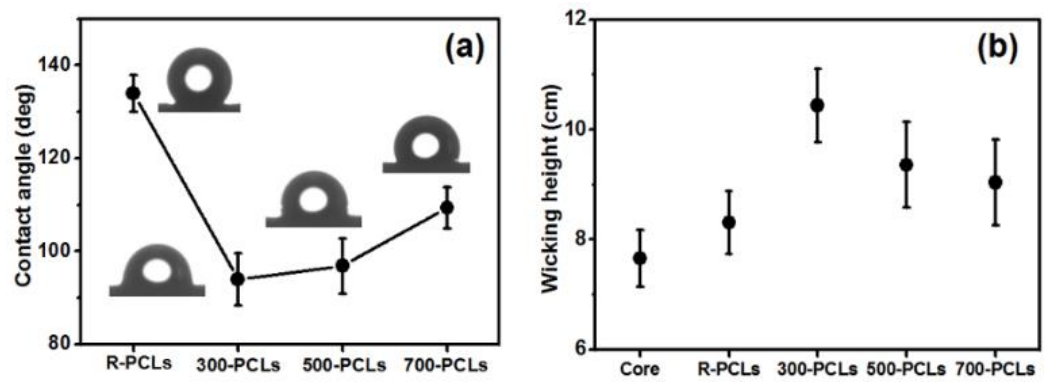

Figure 4 Effect of arrangement of surface PCL nanofibers on water contact angle (a) and wicking height

(b) for the different scaffolds.

\subsection{Effect of nanofiber arrangement on mechanical properties of different scaffolds}

Figure 5a shows the stress-strain curve and Young's modulus of different scaffolds. It is illustrated that the Young's modulus of different scaffolds remains unchanged at the initial elastic region. However, tensile strength and break strain of 300-PCLs (372 MPa; 28\%), 
(b)

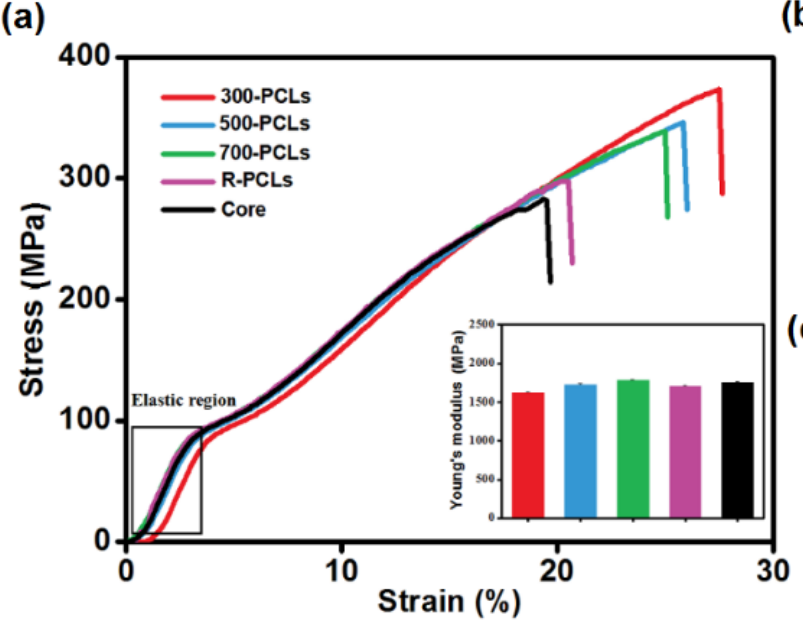

c)
500-PCLs (345 MPa; 26\%), and 700-PCLs (335 MPa; 25\%) increase compared to the core yarn (290 MPa; 19\%) because of the inclusion of electrospun PCL nanofibers. The PCL nanofibers broke after the failure of the core yarn so a smaller alignment angle of the nanofibers on the surface of the scaffolds could lead to a higher tensile strength and break strain of A-PCLs (Figure 5b, c).
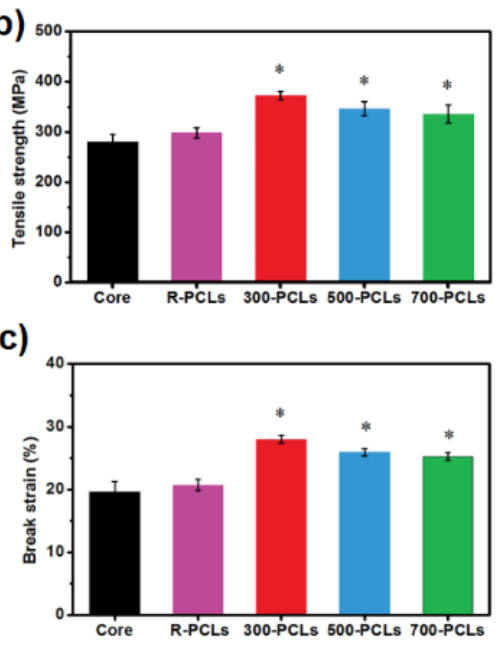

Figure 5 Stress-strain curve, Young's modulus (a), tensile strength (b), and break strain (c) of different scaffolds. $*, p<0.05$.

\subsection{Cellular morphology on different scaffolds}

In vitro biological assessments were carried out by using BALB/3T3 cells. The morphology of cells on different scaffolds was visualized by FE-SEM and CLSM after 3 days of cell seeding. Figure 6 shows the FE-SEM images of cells on the surface of 300-PCLs, 500-PCLs, 700-PCLs, and R-PCLs scaffolds. Clearly BALB/3T3 cells prefer to attach to and grow on the biotopographic cues provided by A-PCLs scaffolds and tend to proliferate along the aligned PCL nanofibers (Figure 6a-c), while the morphology of cells on the R-PCLs scaffolds show an irregular oval form (Figure 6d). The growth patterns of BALB/3T3 cells on different biotopographic cues of scaffolds were characterized by measuring the aspect 
ratio of the cell lines in the FE-SEM images (Figure 6e). Cellular aspect ratio on 300-PCLs (8.20 \pm 1.5$)$, 500-PCLs $(7.31 \pm 0.33)$, and 700-PCLs $(6.91 \pm 0.89)$ is significantly higher than that on R-PCLs (1.75 \pm 0.29$)$ shown in Figure $6 f$.

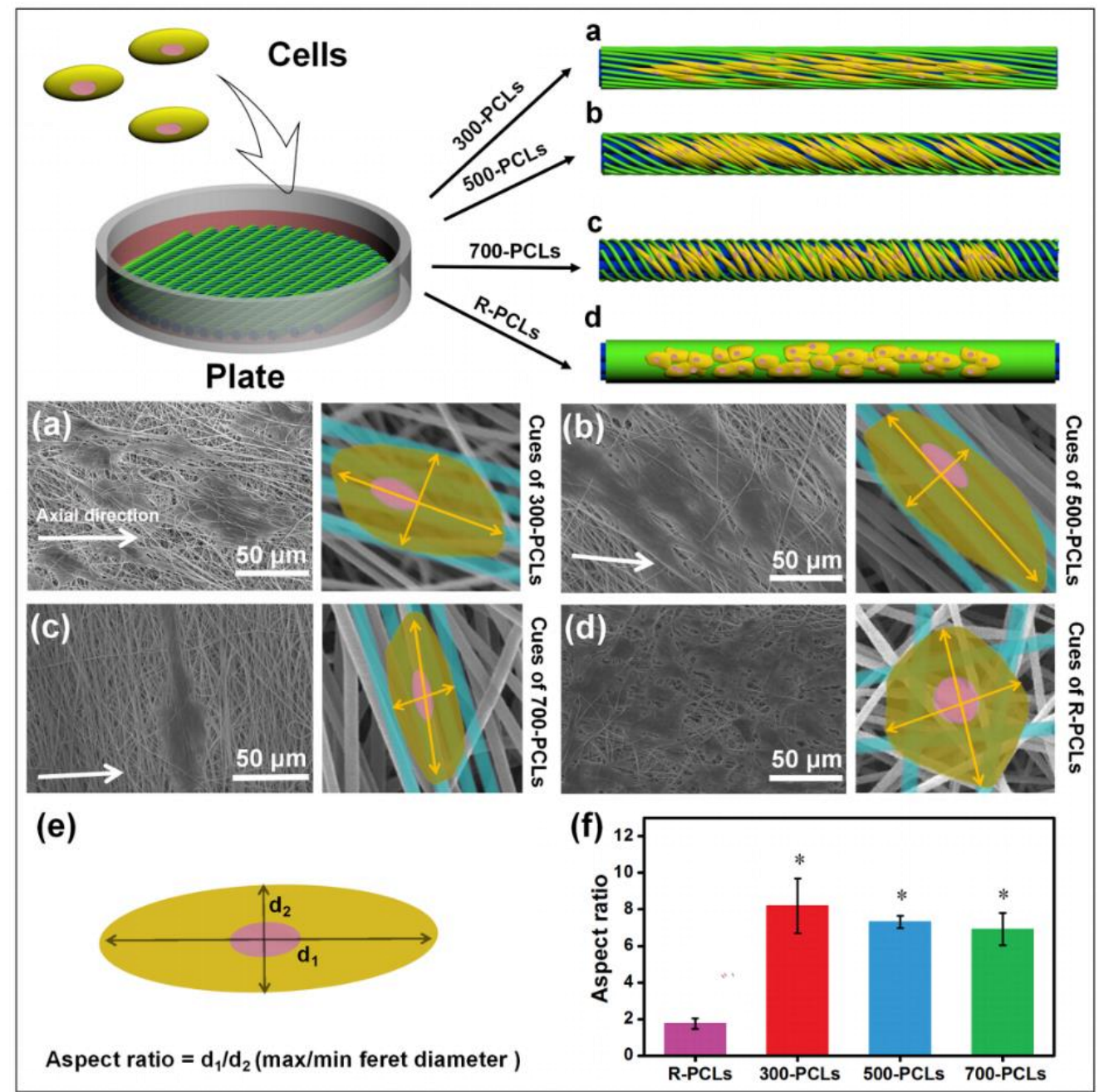

Figure 6 FE-SEM image of morphology of BALB/3T3 cells on different scaffolds (300-PCLs (a), 500-PCLs (b), 700-PCLs (c), R-PCLs (d)) after 3 days of cell culture, and statistical analysis of aspect ratio of cell lines on A-PCLs and R-PCLs. *, $p<0.05(\mathrm{e}, \mathrm{f})$.

Actin behavior was regarded to play a great role on the adhesion, migration and proliferation of cells. ${ }^{[47,48]}$ Figure 7a simulations that the biotopographic cues of scaffolds can induce the contact direction of actin, and determine the direction of cell secretion of ECM. At a relatively high magnification as shown in Figure 7b-d, BALB/3T3 cells grow 

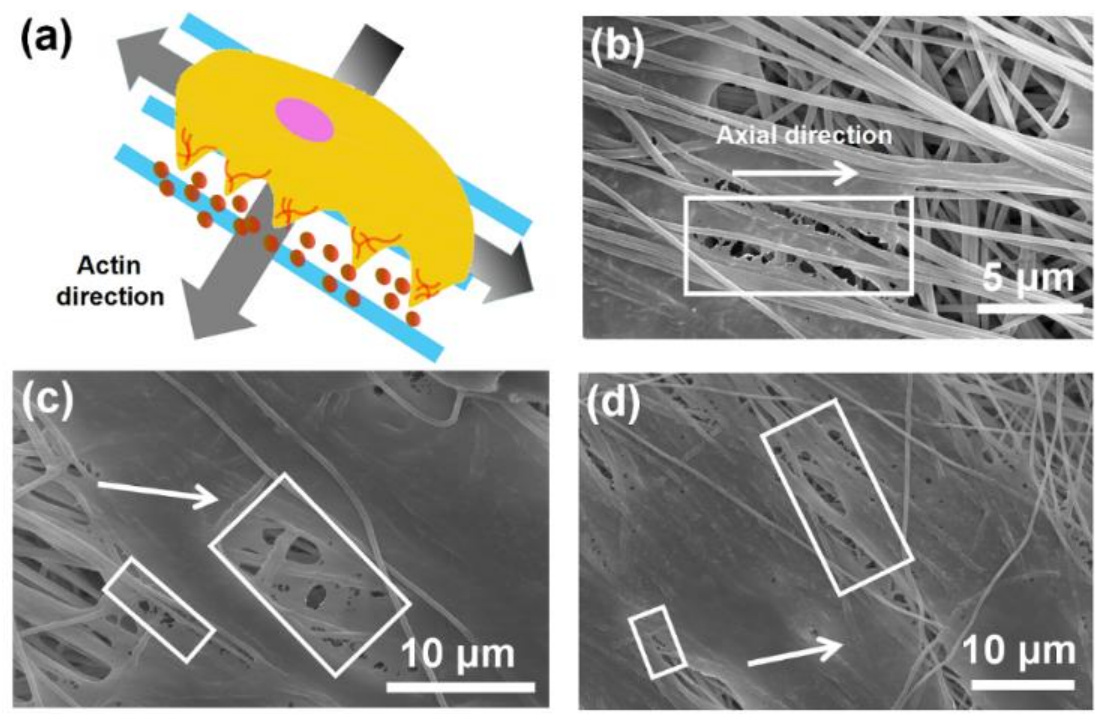

Figure 7 Simulations of the cell elongation and actin organization (a), and FE-SEM images of BALB/3T3 cells on 300-PCLs (b), 500-PCLs (c) and 700-PCLs (d) after 3 days of cell seeding. 

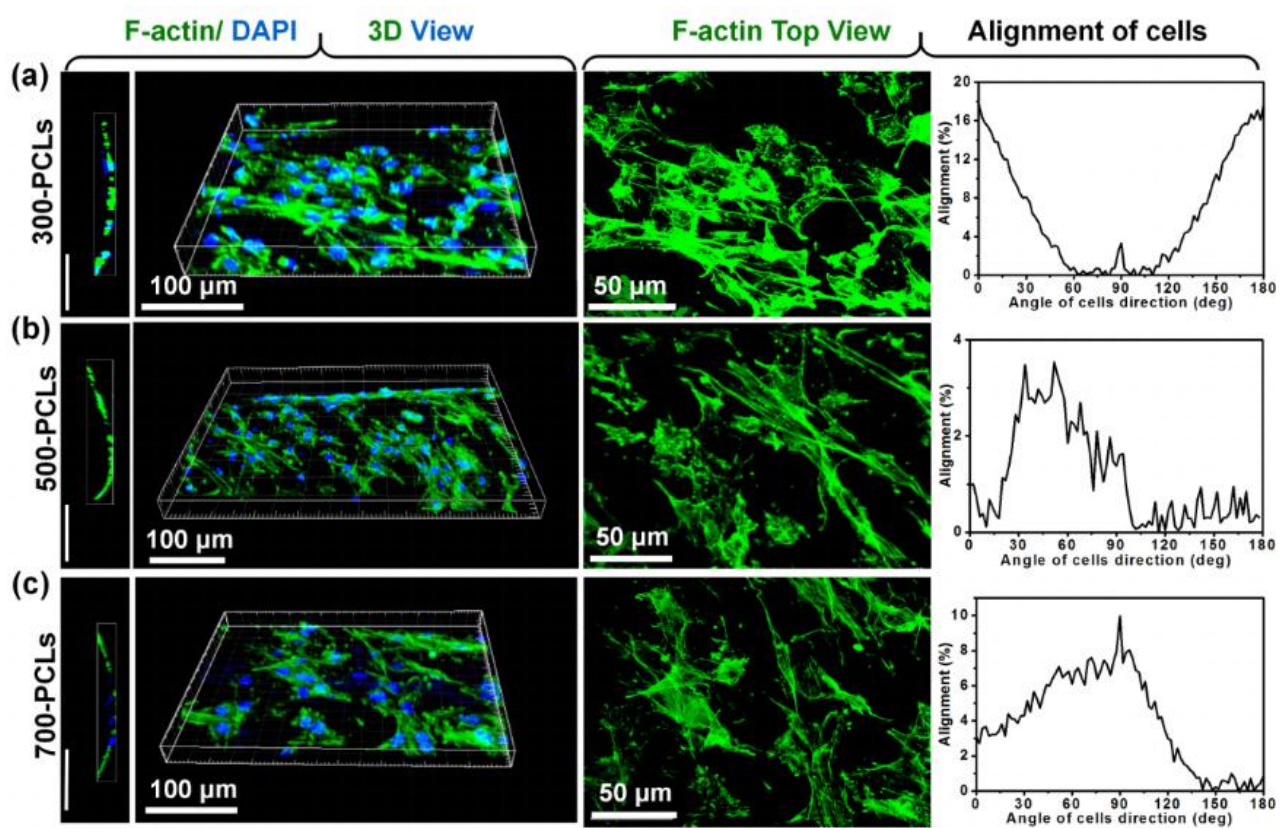

Figure 8 CLSM images of 3D view and top view for the F-actin and DAPI staining morphology of BALB/3T3 cells after 3 days of culture, and relative cell alignment curves of 300-PCLs (a), 500-PCLs (b), 700-PCLs (c).

\subsection{Cell proliferation on different scaffolds}

MTT assay was carried out to evaluate the cell proliferation of BALB/3T3 cells on 300-PCLs, 500-PCLs, and 700-PCLs. Figure 9a shows that BALB/3T3 cells proliferate slowly at 1 day of culture, and then the proliferation rate increases during the period from 3 to 5 days. The proliferation of cells on these scaffolds does not show any significant difference at the same culture time, suggesting that A-PCLs have the same trend for proliferation of BALB/3T3 cells. In comparison to R-PCLs and Core (TCP as control), A-PCLs have a significant proliferation difference as shown in Figure 9b, in which MTT result of BALB/3T3 on A-PCLs refers to the mean value on 300-PCLs, 500-PCLs, and 700-PCLs. It is observed that proliferation of control group is higher than that of the other three scaffolds at the beginning of culture for $\mathrm{BALB} / 3 \mathrm{~T} 3$, because the cells need to adapt to new environment. But there is a significant difference between nanofiber covered yarns 

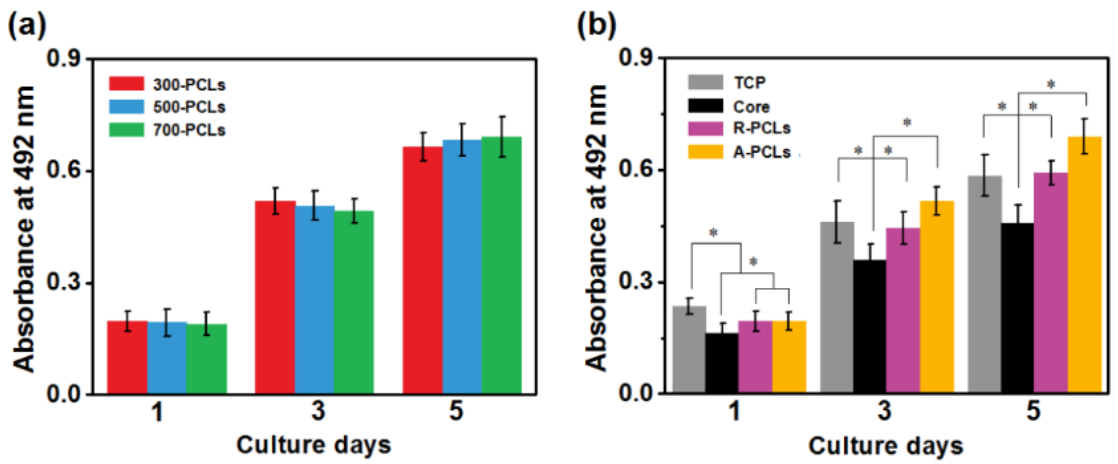

Figure 9 MTT results of BALB/3T3 on A-PCLs (a), and various substrates (b) after 1, 3, and 5 days of cell culture. *, $p<0.05$.

\section{Conclusions}

In this work, A-PCLs were developed for tissue engineering scaffolds by a novel electrospinning process which could be adjusted to control the alignment direction of nanofibers on the outer periphery of the core material. The core and covered material can be selected according to different tissue engineering requirements. The prepared scaffolds possessed well aligned nanofibers with a large porosity and hydrophilicity which were found to be advantageous to cell growth. In vitro biological performance showed that cell adhesion and proliferation were evidently promoted on the A-PCLs scaffolds, and cells were able to 
identify the biotopographic cues provided by the surface aligned nanofibers. Furthermore, the A-PCLs had sufficient mechanical properties for weaving or other post-treatments. Therefore, these core-shell structure of A-PCLs scaffolds have significant potential for constructing different 3D tissue bioengineered structures.

\section{Supporting Information}

Supporting Information is available from the Wiley Online Library or from the author.

\section{Acknowledgments}

This work was supported by grants from National Natural Science Foundation of China (51503168), Shaanxi Innovation Talent Promotion Program-Project for Youth New Star of Science and Technology (2017KJXX-23), China Scholarship Council (201708610031), Disciplinary Construction Fund for Textile Science and Engineering of Xi'an Polytechnic University (10709-0821), Xi'an Polytechnic University Innovation Fund for Graduate Students (CX201729), and Special Funding for Postdoctoral Innovation Project in Shandong Province (201504).

\section{Conflict of Interest}

The authors declare no conflict of interest

\section{References}

[1] R. Langer, J. P. Vacanti, Science 1993, 260, 920.

[2] R. O. Hynes, Science 2009, 326, 1216.

[3] E. H. Sage, J. Clin. Invest. 2001, 107, 781.

[4] D. H. Kim, P. P. Provenzano, C. L. Smith, A. Levchenko, J. Cell Biol. 2012, 197, 351.

[5] L. L. Qiu, C. Choong, Tissue Eng. Part B 2013, 19, 485. 
[6] D. Dado, S. Levenberg, Semin. Cell Dev. Biol. 2009, 20, 656.

[7] D. Phu, L. S. Wray, R. V. Warren, R. C. Haskell, E. J. Orwin, Tissue Eng. Part A 2011, 17, 799.

[8] V. Chaurey, F. Block, Y. H. Su, P. C. Chiang, E. Botchwey, C. F. Chou, N. S. Swami, Acta Biomater. 2012, 8, 3982.

[9] L. H. Han, X. Tong, F. Yang, Adv. Mater. 2014, 26, 1757.

[10] A. Autissier, V. C. Le, C. Pouzet, F. Chaubet, D. Letourneur, Acta Biomater. 2010, 6, 3640.

[11] T. Paulraj, N. Feoktistova, N. Velk, K. Uhlig, C. Duschl, D. Volodkin, Macromol. Rapid Comm. 2014, 35, 1408.

[12] T. M. Hsieh, C. W. Ng, K. Narayanan, A. C. Wan, J. Y. Ying, Biomaterials 2010, 31, 7648.

[13] S. Chen, T. Nakamoto, N. Kawazoe, G. Chen, Biomaterials 2015, 73, 23.

[14] F. Pati, D. H. Ha, J. Jang, H. H. Han, J. W. Rhie, D. W. Cho, Biomaterials 2015, 62, 164.

[15] C. A. Lawrence, Woodhead Pubulishing, UK 2014.

[16] H. G. S. Ayaz, A. Perets, H. Ayaz, K. D. Gilroy, M. Govindaraj, D. Brookstein, P. Lelkes, Biomaterials 2014, 35, 8540 .

[17] F. T. Moutos, L. E. Freed, F. Guilak, Nat. Mater. 2007, 6, 162.

[18] T. A. Desai, Med. Eng. Phys. 2000, 22, 595.

[19] A. Formhals, 1934, USA Patent 1975504.

[20] T. Subbiah, G. S. Bhat, R. W. Tock, S. Parameswaran, S. S. Ramkumar, J. Appl. Polym. Sci. 2005, 96, 557. 
[21] E. D. Boland, G. E. Wnek, D. G. Simpson, K. J. Pawlowski, G. L. Bowlin, J. Macromol. Sci. A 2001, 38, 1231.

[22] H. Cao, K. Mchugh, S. Y. Chew, J. M. Anderson, J. Biomed. Mater. Res. A 2010, 93, 1151.

[23] J. Radhakrishnan, A. A. Kuppuswamy, S. Sethuraman, J. Biomed. Nanotechnol. 2015, 11, 512.

[24] K. J. Aviss, J. E. Gough, S. Downes, Eur. Cells Mater. 2010, 19, 193.

[25] S. Y. Chew, R. Mi, A. Hoke, K. W. Leong, Biomaterials 2008, 29, 653.

[26] C. Y. Xu, R. Inai, M. Kotaki, S. Ramakrishna, Biomaterials 2004, 25, 877.

[27] J. Chen, J. Ge, B. Guo, K. Gao, P. X. Ma, J. Mater. Chem. B 2016, 4, 2477.

[28] S. Wu, B. Duan, X. Qin, J. T. Butcher, Acta Biomater. 2017, 51, 89.

[29] Y. Wu, L. Wang, B. Guo, P. X. Ma, ACS Nano 2017, 11, 5646.

[30] L. Wang, Y. Wu, B. Guo, P. X. Ma, ACS Nano 2015, 9, 9167.

[31] P. A. Mouthuy, N. Zargar, O. Hakimi, E. Lostis, A. Carr, Biofabrication 2015, 7, 025006.

[32] L. Li, J. Ge, L. Wang, B. Guo, P. M. Ma, J. Mater. Chem. B 2014, 2, 6119.

[33] J. Wu, C. Huang, W. Liu, A. Yin, W. Chen, C. He, H. Wang, S. Liu, C. Fan, G. L. Bowlin, X. Mo, J. Biomed. Nanotechnol. 2014, 10, 603.

[34] D. Li, X. Pan, B. Sun, T. Wu, W. Chen, C. Huang, Q. Ke, H. A. EI-Hamshary, S. S. Al-Deyab, X. Mo, J. Mater. Chem. B 2015, 3, 8823.

[35] F. Zamani, M. Amanitehran, M. Latifi, M. A. Shokrgozar, A. Zaminy, J. Biomed. Mater. Res. A 2014, 102, 506. 
[36] S. Liu, J. Wu, X. Liu, D. Chen, G. L. Bowlin, L. Cao, J. Lu, F. Li, X. Mo, C. Fan, Mater. Res. A 2015, 103, 581.

[37] J. Chen, M. Yu, B. Guo, P. X. Ma, Z. Yin, J. Colloid Interf. Sci. 2018, 514, 517.

[38] R. B. Martin, D. B. Burr, N. A. Sharkey, D. P. Fyhrie, New York: Springer, 1998.

[39] C. K. Liu, H. J. He, R. J. Sun, Y. Feng, Q. S. Wang, Mater. Des. 2016, 112, 456.

[40] J. Pu, K. Komvopoulos, Acta Biomater. 2014, 10, 2718.

[41] C. E. Ayres, B. S. Jha, H. Meredith, J. R. Bowman, G. L. Bowlin, S. C. Henderson, D. G. Simpson, J. Biomater. Sci. Polym. Ed. 2008, 19, 603.

[42] B. B. Manda, S. C. Kundu, Biomaterials 2009, 30, 2956.

[43] B. Li, C. Liu, F. Zhou, X. Mao, R. Sun, Biotechnol. Lett. 2018, 12, 4287.

[44] W. J. Li, C. T. Laurencin, E. J. Caterson, R. S. Tuan, F. K. Ko, J. Biomed. Mater. Res. A 2002, 60, 613 .

[45] A. Thorvaldsson, H. Stenhamre, P. Gatenholm, P. Walkenström, Biomacromolecules 2008, 9, 1044.

[46] L. Wang, Y. Wu, T. Hu, B. Guo, P. X. Ma, Acta Biomater. 2017, 59, 68.

[47] T. D. Pollard, J. A. Cooper, Science 2009, 326, 1208.

[48] M. Emmert, P. Witzel, D. Heinrich, Soft Matter 2016, 12, 4287. 


\section{Supporting Information}

to access/download
information.doc

\section{Click here to access/download
Supporting Information
support information.doc \\ Click here to access/download
Supporting Information
support information.doc Click here to access/download
Supporting Information
support information.doc

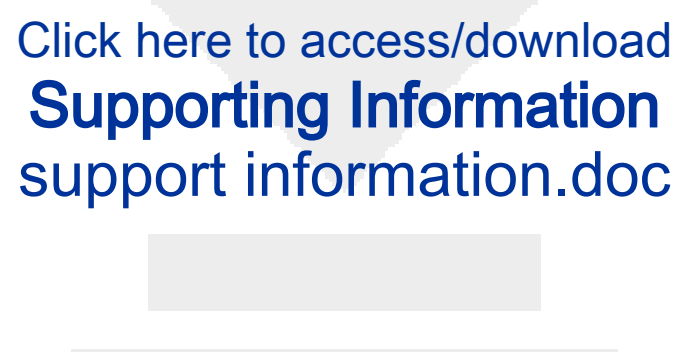

$x^{2}$

$-$

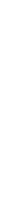


Click here to access/download Production Data Production data.rar 